\title{
Psychosocial Factors and Rectal Hyposensitivity
}

TO THE EDITOR: We read with interest the review article by Burgell and Scott ${ }^{1}$ regarding rectal hyposensitivity ( $\left.\mathrm{RH}\right)$. $\mathrm{RH}$ is clinically defined as elevated sensory thresholds to simple rectal balloon distension with a hand-held syringes. More exact diagnotic method is a computer-controlled barostat. ${ }^{1}$ Barostat testing of rectal sensation has been reported to be reproducible. ${ }^{2}$

$\mathrm{RH}$ has been reported in $18 \%$ to $68 \%$ of patients with functional constipation, and significantly related to functional anorectal obstruction, although $\mathrm{RH}$ is an etiology for or a consequence of functional anorectal obstruction. ${ }^{3}$ However it is noted that the diagnostic method most commonly used in assessment of sensory function is not barostat testing but simple balloon test. Recently, Lee et $\mathrm{al}^{4}$ reported that $\mathrm{RH}$ and functional anorectal outlet obstruction are common entities but appear not to be significantly associated. Contrary to previous knowledge, $\mathrm{RH}$ was not significantly related to functional factors including dyssynergic defecation, rectocele and rectal intussusception in the study using gold standard method (barostat). We also would like to show the previous our barostat study regarding to the relation-

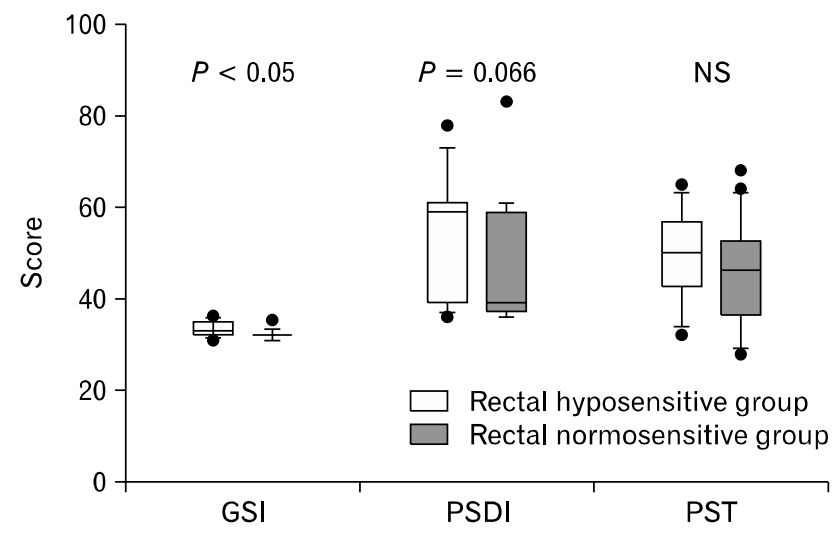

Figure. Asscoiation with psychosocial factors. There is a significant difference in the mean value for global scale index between rectal hyposensitivity and normosensitive group. GSI, global scale index; PSDI, positive symptom distress index; PST, positive symptom total. ships between the $\mathrm{RH}$ and clinical, functional and psychosocial factors. In 49 patients with functional constipation based on Rome II criteria, we performed symptom questionnaires, Symptom Checklist 90-Revision (SCL-90-R), rectal sensitivity test using barostat, colon transit time, anaorectal manometry, balloon expulsion test and defecography. Twelve patients (24\%) showed RH. There were no significant differences in age, gender, stool form using Bristol scale, colon transit time, abnormal balloon expulstion test, ratio of slow transit constipation and ratio of pelvic floor dyssynergia. There is a tendency to increase in depression score in $\mathrm{RH}$ group than rectal normosensitive $(\mathrm{N})$ group (54.1 \pm 10.7 vs. $48.2 \pm 10.2, P=0.094)$. Global severity index was significantly increased in $\mathrm{RH}$ group than $\mathrm{N}$ group (33.4 \pm 1.7 vs. $32.2 \pm 1.0, P<0.05)$ (Figure). The positive symptom distress index also had a tendency to increase in $\mathrm{RH}$ group than $\mathrm{N}$ group $(54.3 \pm 13.0$ vs. $48.2 \pm 12.5, P=0.066)$. Further study is needed to elucidate the relationship between rectal hyposensitivity and psychosocial factors.

Tae Hee Lee and Joon Seong Lee Institute for Digestive Research, Soonchunhyang University College of Medicine, Seoul, Koea

1. Burgell RE, Scott SM. Rectal hyposensitivity. J Neurogastroenterol Motil 2012;18:373-384.

2. Cremonini F, Houghton LA, Camilleri M, et al. Barostat testing of rectal sensation and compliance in humans: comparison of results across two centres and overall reproducibility. Neurogastroenterol Motil 2005;17:810-820.

3. Gladman MA, Lunniss PJ, Scott SM, Swash M. Rectal hyposensitivity. Am J Gastroenterol 2006;101:1140-1151.

4. Lee TH, Lee JS, Hong SJ, et al. Rectal hyposensitivity and functional anorectal outlet obstruction are common entities in patients with functional constipation but are not significantly associated. Korean J Intern Med 2013;28:54-61.

Conflicts of interest: None. 